\title{
Design of a Tag Antenna for UHF RFID Food Systems
}

\author{
Dong-Beom Shin ${ }^{1} \cdot$ Jung Nam Lee ${ }^{2, *} \cdot$ Heyung-Sub Lee ${ }^{1} \cdot$ Sang-Yeoun Lee ${ }^{1} \cdot$ Byeong-Sam Kim ${ }^{3}$
}

\begin{abstract}
This paper proposes a tag antenna for radio frequency identification (RFID) food system. The RFID tag antenna is designed and fabricated based on the rectangular loop concept used in the UHF band (Korean and Japanese standards, 916.7-923.5 MHz). The proposed tag antenna is composed of a radiation patch, sensor tag chip, temperature sensor, oscillator, and battery. We conjugated matching between the tag antenna and the sensor tag using a U-shaped stub. Details of the proposed tag antenna design and the simulated and measured results are presented and discussed.
\end{abstract}

Key Words: Food Systems, Semi-Active Sensor, UHF RFID.

\section{INTRODUCTION}

Radio frequency identification (RFID) now finds applications in many areas, including logistics tracing, traffic control, environmental surveillance, and medical and grocery tracking. The RFID system consists of a reader and a tag, and the UHF RFID system operates at the bands of North America (902-928 MHz), Europe (865-867 MHz), Japan (916.7-923.5 MHz), and Korea (917-923.5 MHz). RFID is classified into passive and active types according to the method used to obtain the energy source of the electric wave. The passive type obtains the transmission energy from the electric wave received from the reader. The active type obtains the transmission energy from the battery. The passive tag has a semi-permanent life, no battery, is inexpensive, and is suitable for short range communication. On the other hand, the active tag can be used for long range communication because the battery is built into the tag.
However, the high price and the battery lifetime currently restrict the use of RFID. Several papers have been published on RFID antennas for both passive and active tags [1-13], such as a shorted micro-strip patch antenna that uses an inductively coupled feed for the UHF RFID tag [2], miniaturization of a rectangular loop antenna using a meander line for RFID tags [3], RFID tag antennas that use an inductively coupling feed [4], a flexible planar RFID tag antenna with low performance degradation from nearby target objects [8], a broadband UHF RFID tag antenna with a rectangular-loop feed and additional patches [9], a planar loop tag antenna with bandwidth enhancement for the UHF RFID system [10], a long range UHF RFID tag with a rectangular metallic cavity structure [11], and a design for an integrated loop coupler and loop antenna for RFID applications [12]. The active RFID can provide long range data transmission because it uses different fields (the environmental monitoring, military, and health care). The requi-

Manuscript received August 1, 2013 ; Revised September 2, 2013 ; Accepted September 23, 2013. (ID No. 20130801-030J)

${ }^{1}$ Smart Things Cognition Research Team, Electronics and Telecommunications Research Institute, Daejeon, Korea

${ }^{2}$ Mobile RF Research Team, Electronics and Telecommunications Research Institute, Daejeon, Korea

${ }^{3}$ Food Safety and Distribution Research Group, Korea Food Research Institute, Sungnam, Korea

"Corresponding Author: Jung Nam Lee (e-mail: jnlee77@etri.re.kr)

This is an Open-Access article distributed under the terms of the Creative Commons Attribution Non-Commercial License (http://creativecommons.org/licenses/by-nc/3.0) which permits unrestricted non-commercial use, distribution, and reproduction in any medium, provided the original work is properly cited.

(C) Copyright The Korean Institute of Electromagnetic Engineering and Science. All Rights Reserved. 
rement for food history management systems is growing due to the increasing importance of food safety problems. The freshness of vegetable, meat, or dairy product is very important. An active RFID tag is attached to the product (a vegetable, meat, and dairy product) that requires refrigeration and the temperature/process of distribution is monitored so that product spoilage can be prevented.

In this paper, we present a design for a semi-active sensor tag antenna for RFID food systems. The proposed tag antenna is composed of a radiation patch, sensor tag chip, temperature sensor, oscillator, and battery. The proposed tag antenna covers the range of $916.7-923.5 \mathrm{MHz}$ (Korean and Japanese standards). We have conjugated matching between the tag antenna and the sensor tag by using a U-shaped stub. The selection of the geometry of the U-shaped stub allows the tag antenna to be tuned to the operating frequency. The simulation and fine tuning of the tag antenna were carried out using commercial high frequency structure simulator (HFSS) software.

\section{TAg Antenna Design}

Fig. 1 shows the geometry of the proposed semi-active sensensor tag antenna for an RFID food system.

The tag antenna is supported by a dielectric substrate of a height equal to $0.8 \mathrm{~mm}$ and a relative dielectric constant

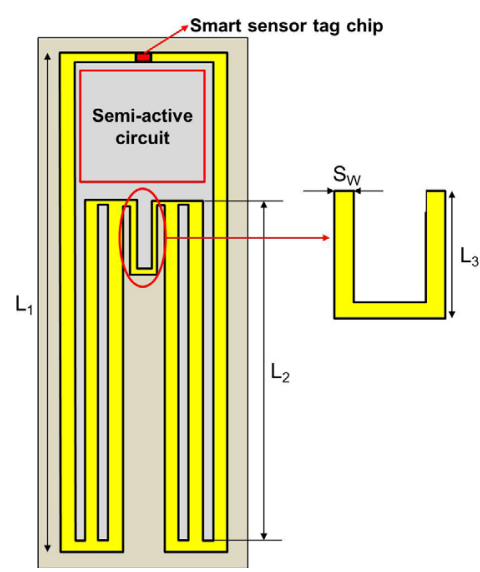

(a)

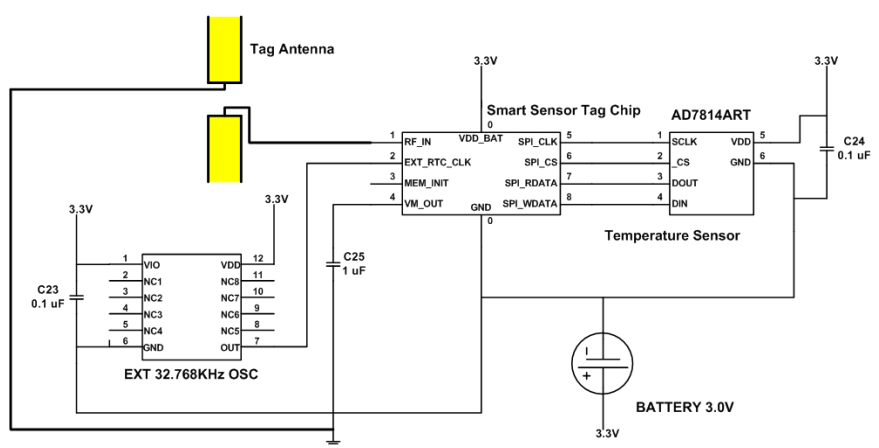

(c)

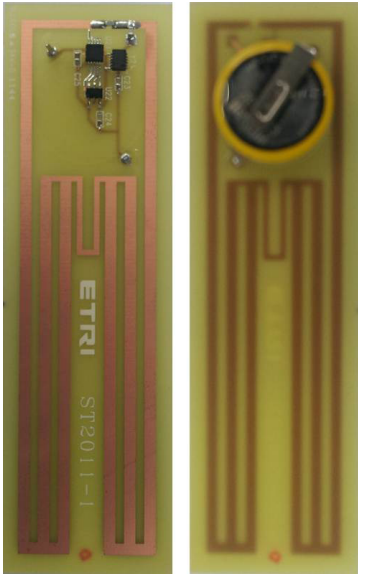

(b)

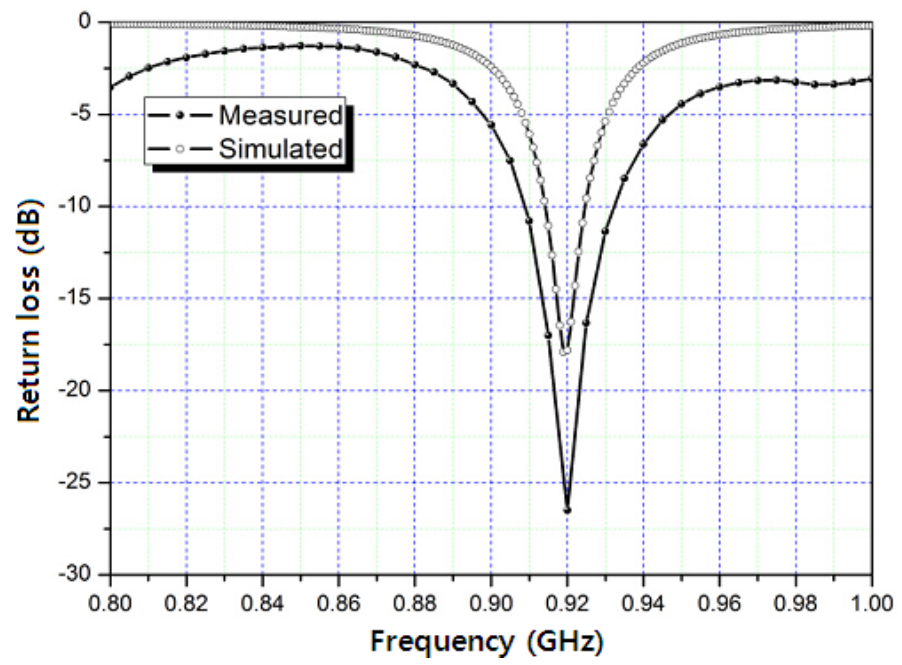

(a)

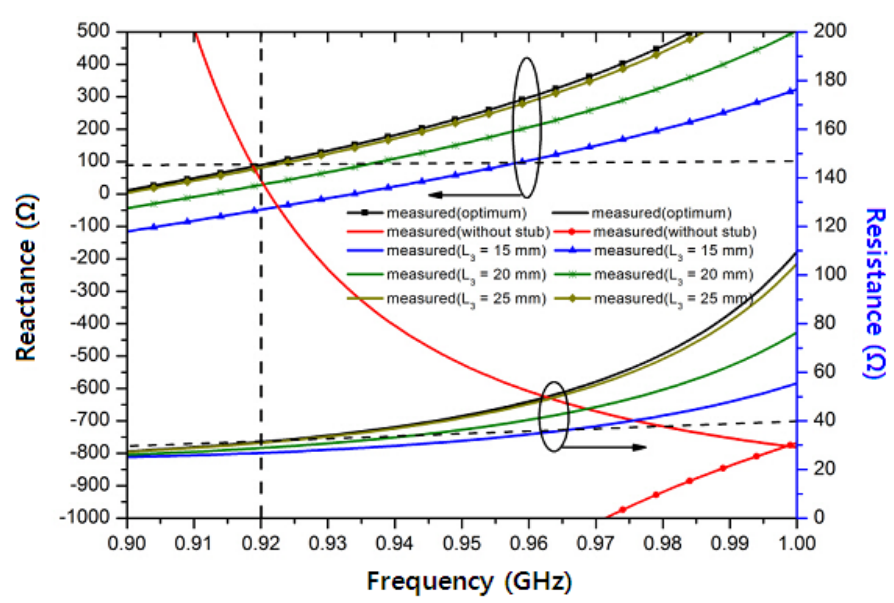

(b)

Fig. 2. Measured results of the semi-active tag antenna. (a) Return loss and (b) input impedance.

of 4.3 (FR-4, loss tangent $=0.025)$. The semi- active circuit is composed of a sensor tag chip (ETRI tag chip), temperature sensor (AD7814ART), oscillator (EXT $32.768 \mathrm{kHz}$ OSC), and battery (CR2023). The oscillator sends a time clock signal to the sensor tag and the temperature sensor measures the temperature attached to the product (a vegetable, meat, or dairy product) according to the setup time. The tag antenna transmits the measured temperature. The tag antenna has dimension of $30 \mathrm{~mm} \times 100 \mathrm{~mm}$, and the optimal design parameters can be chosen as $L_{1}=93.5 \mathrm{~mm}$, $L_{2}=64 \mathrm{~mm}, L_{3}=24.5 \mathrm{~mm}$, and $S_{W}=1 \mathrm{~mm}$. The microchip used is an ETRI chip with an impedance of $Z c=40-$ $j 87 \Omega$ at $920 \mathrm{MHz}$. To conjugate matching between the tag antenna and the sensor tag, we have used U-shaped stub. By selecting the geometry of the U-shaped stub, the tag antenna can be tuned to the operating frequency.

\section{Measured And Simulated Results}

Fig. 2 shows the simulated and measured results of the

Fig. 1. Geometry of the proposed semi-active tag antenna. (a) Tag antenna, (b) photograph, and (c) semi-active circuit. 


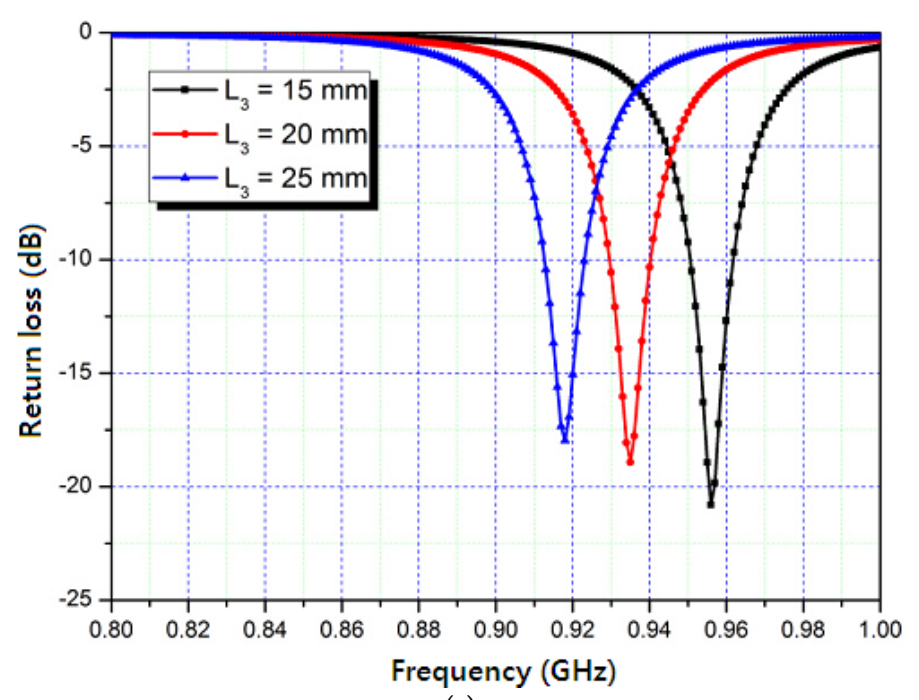

(a)

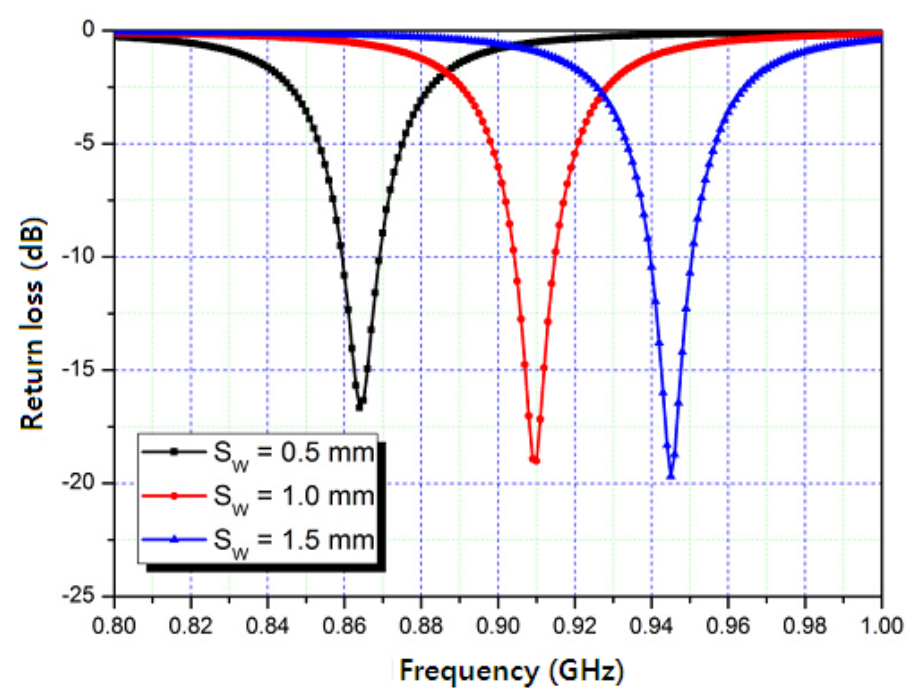

(b)

Fig. 3. Simulated return losses versus frequency for different sizes of U-shaped stubs. (a) $L_{3}$ and (b) $S_{W}$.

proposed tag antenna. The simulation results were obtained from commercial software on an Ansys HFSS, and the reliability of the obtained results was confirmed.

Fig. 2(a) shows the results of a tag antenna with a sensor tag chip, temperature sensor, oscillator, and battery, operating at a frequency of $920 \mathrm{MHz}$. The measured bandwidth for return loss $<10 \mathrm{~dB}$ is $20 \mathrm{MHz}(910-930 \mathrm{MHz})$, which covers the $6.8 \mathrm{MHz}$ bandwidth requirements of the Korean and Japanese standards for the UHF RFID band (916.7923.5 $\mathrm{MHz}$ ). The measured bandwidth for return loss $<5$ $\mathrm{dB}$ is $50 \mathrm{MHz}(900-950 \mathrm{MHz})$, which covers the $26 \mathrm{MHz}$ bandwidth requirements of the North America band (902$928 \mathrm{MHz}$ ). The impedance responses of the tag antenna and of the ETRI chip are shown in Fig. 2(b). As $L_{3}$ is increases, the input resistance and reactance also increase at the center frequency $(920 \mathrm{MHz})$. However, without a U-shaped stub, no matching occurred between the tag antenna and the

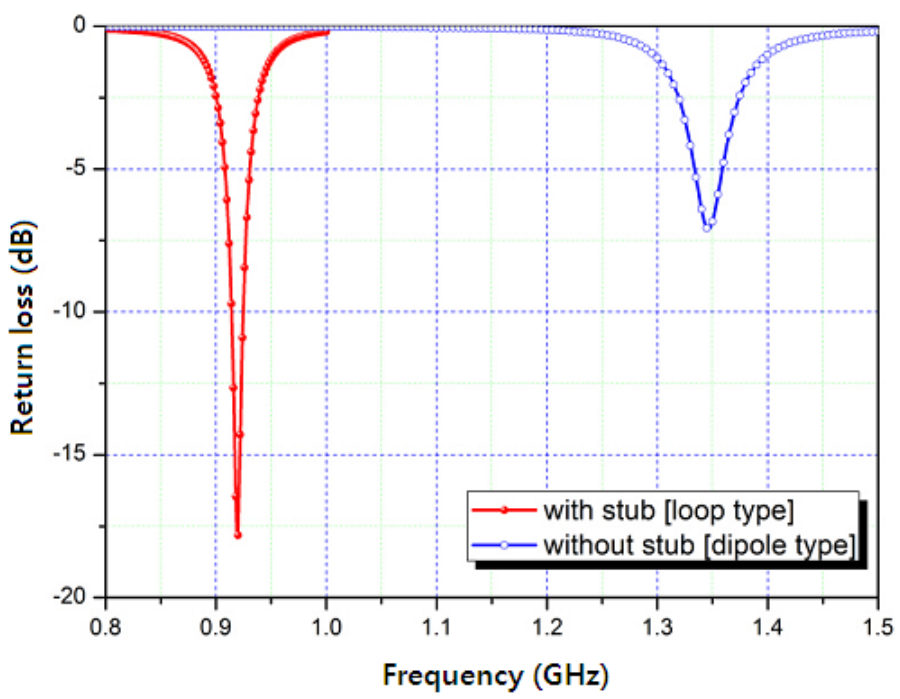

Fig. 4. Simulated with and without the U-shaped stub.

chip. As the $L_{3}$ value is $24.5 \mathrm{~mm}$, it became a tag antenna and chip with conjugate matching $(32+j 87 \Omega$ at $920 \mathrm{MHz})$.

We simulated the design variable for the proposed tag antenna structure. Fig. 3(a) shows that as the length $L_{3}$ is increased, the operating frequency band moves to a lower frequency. The optimized value in this design is $24.5 \mathrm{~mm}$. Fig. 3(b) shows that as the width $S_{W}$ is increased, the operating frequency band moves to a higher frequency. The optimized value in this design is $1.0 \mathrm{~mm}$. The results shows that the whole antenna structure does not need to be changed, and the frequency can be controlled quite simply.

The simulated return loss of the designed antenna with and without the U-shaped stub is shown in Fig. 4. With the $\mathrm{U}$-shaped stub, the antenna is a loop type. Without the Ushaped stub, antenna is dipole type. As shown in the figure, when the U-shaped stub is present, the proposed tag antenna satisfies the operating frequency. This confirms that the U-shaped stub is an important element in the tag antenna and chip with conjugate matching.

Fig. 5 shows the radiation patterns of the proposed tag antenna, measured in an anechoic chamber at the Korea RFID/USN Center, Incheon, Korea. The radiation patterns in the E-plane are very dipole-like, while those in the H-plane are nearly omni-directional for all frequencies. In addition, the radiation patterns are stable across the respective operating frequency bands. The realized gain values for these three cases at 917, 920, and $924 \mathrm{MHz}$ are 3.35, 3.35, and 2.53 $\mathrm{dBi}$, respectively.

Fig. 6(a) shows the setup environment for groceries temperature monitoring. As shown in figure, the groceries, a reader antenna, and a semi-active tag antenna are positioned inside the shielding box. In this experiment, the groceries used were meat and a semi-active tag antenna was adhered to the top for the meat. The separation distance between the reader antenna and the semi-active tag antenna was $50 \mathrm{~cm}$, and it measured the temperature of the meat at an interval of 10 minutes. Fig. 6(b) shows that this time interval after 


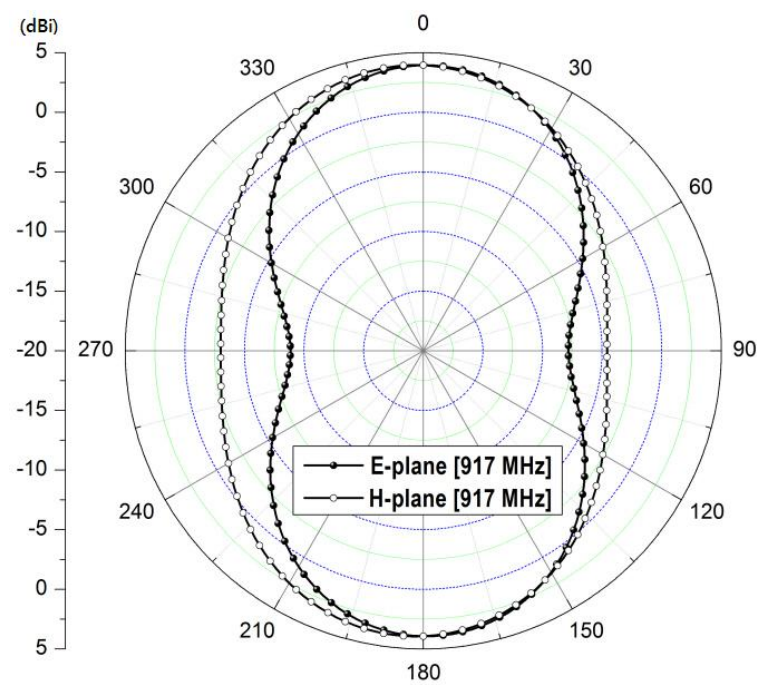

(a)

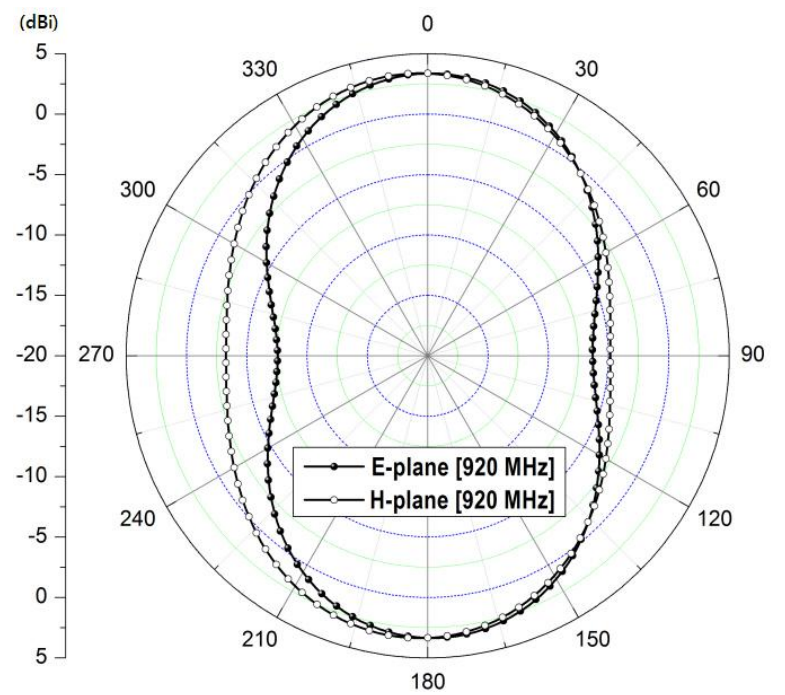

(b)

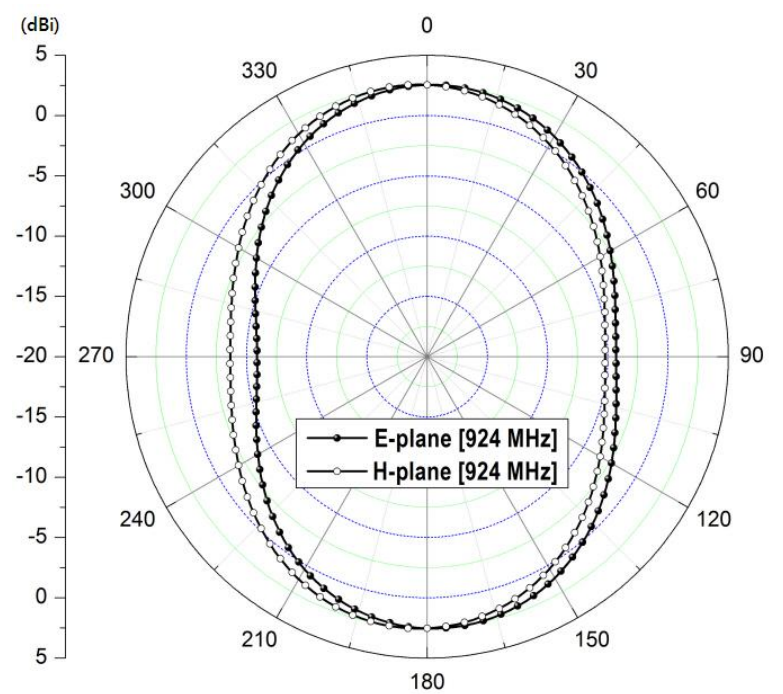

(c)

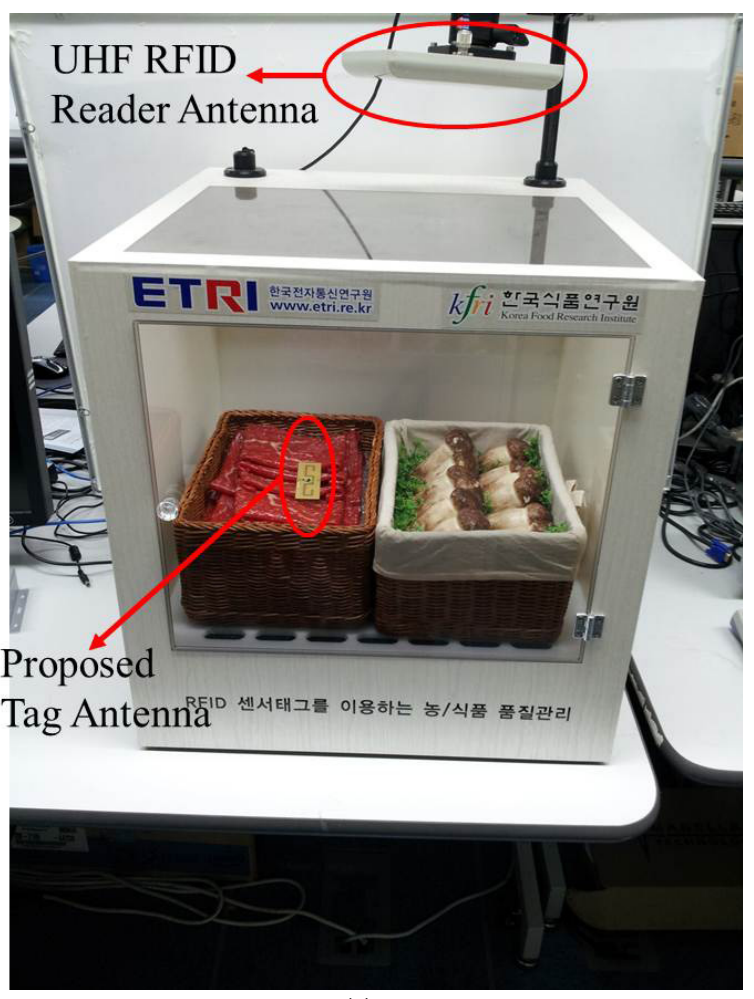

(a)

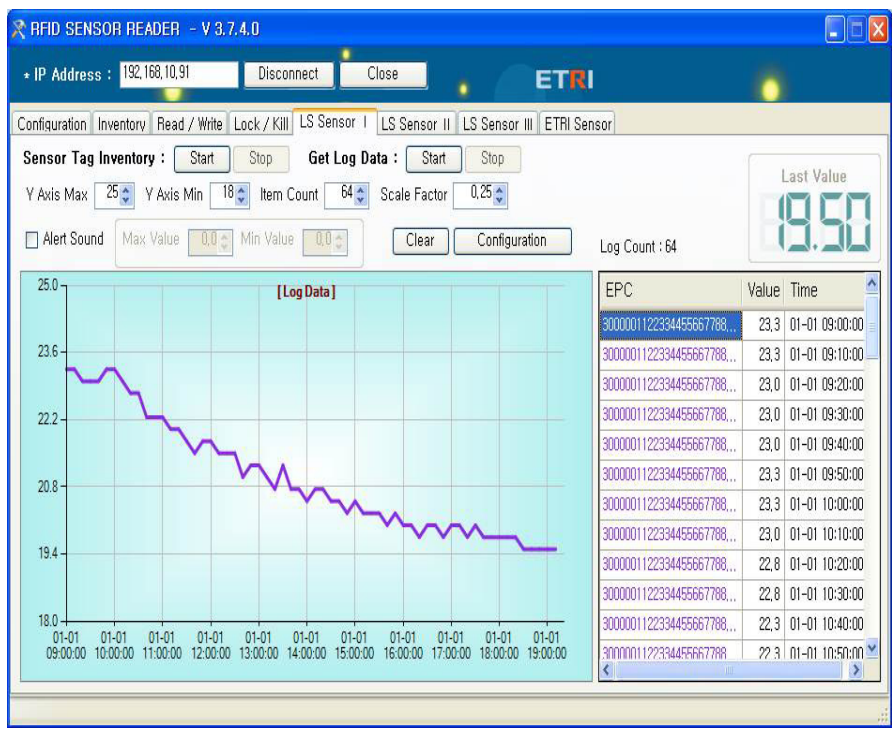

(b)

Fig. 6. Measured results of the tag identification. (a) The setup environment for grocery temperature monitoring and (b) measured results for the grocery temperatures.

setup essentially provided temperature measurements on a real-time basis. Thus, the proposed tag antenna will be valuable for providing a real-time location for groceries and maintaining their freshness.

We compared the proposed tag antenna with existing temperature monitoring tag antennas. Table 1 shows that even though the proposed system is a semi-active structure, it has a very long read range.
Fig. 5. Measured radiation patterns. (a) $914 \mathrm{MHz}$, (b) $920 \mathrm{MHz}$, and (c) $924 \mathrm{MHz}$. 
Table 1. Comparison with other tag antennas

\begin{tabular}{ccccc}
\hline Tag antennas & Structure & Size & $\begin{array}{c}\text { Read } \\
\text { range } \\
(\mathrm{m})\end{array}$ & $\begin{array}{c}\text { Frequency } \\
(\mathrm{MHz})\end{array}$ \\
\hline CAEN A927Z & $\begin{array}{c}\text { Semi- } \\
\text { passive }\end{array}$ & $130.4 \times 23.4 \times 12.7$ & 10 & $860-928$ \\
TMT-8500 & Active & $94 \times 58 \times 14$ & 100 & $902-928$ \\
PowerTMP SL & Active & $85 \times 54 \times 0.9$ & 40 & $860-960$ \\
Proposed & $\begin{array}{l}\text { Semi- } \\
\text { active }\end{array}$ & $100 \times 30 \times 0.8$ & 30 & $\mathbf{9 0 0 - 9 5 0}$ \\
\hline
\end{tabular}

\section{CONCLUSION}

Designing a semi-active sensor tag antenna for RFID food system is challenging. The proposed tag antenna has been designed, fabricated, and characterized for UHF RFID communication applications. It is composed of a radiation patch, sensor tag chip, temperature sensor, oscillator, and battery. We conjugated matching between the tag antenna and the sensor tag by using a U-shaped stub. A semi-active tag antenna was adhered to the top of meat and this allowed real-time measurement of the meat temperature. This tag antenna will be useful in systems for real-time grocery location and for maintaining freshness.

This work was supported by the IT and R\&D program of MKE/KEIT (10035239, Development of ultralight low-power RFID secure platform) and KFRI (E122500, Development of u-Food System), Korea.

\section{REFERENCES}

[1] K. V. S. Rao, P. V. Nikitin, and S. F. Lam, "Antenna design for UHF RFID tags: a review and a practical application," IEEE Transactions on Antennas and Propagation, vol. 53, no. 12, pp. 3870-3876, Dec. 2005.

[2] J. S. Kim, W. Choi, G. Y. Choi, C. S. Pyo, and J. S. Chae, "Shorted microstrip patch antenna using inductively coupled feed for UHF RFID tag," ETRI Journal, vol. 30, no. 4, pp. 600-602, Aug. 2005.

[3] H. K. Ryu and J. M. Woo, "Miniaturisation of rectangular loop antenna using meander line for RFID tags," Electronics Letters, vol. 43, no. 7, pp. 372-373, 2007.
[4] H. W. Son and C. S. Pyo, "Design of RFID tag antennas using an inductively coupling feed," Electronics Letters, vol. 41, no. 18, pp. 994-996, 2005.

[5] A. Ferrer-Vidal, A. Rida, S. Basat, Y. Li, and M. M. Tentzeris, "Integration of sensors and RFID's on ultralow-cost paper-based substrates for wireless sensor networks applications," in Proceedings of the 2nd IEEE Workshop on Wireless Mesh Networks, Reston, VA, 2006, pp. $126-128$.

[6] E. Abad, S. Zampolli, S. Marco, A. Scorzoni, B. Mazzolai, A. Juarros, D. Gomez, I. Elmi, G. Cardinali, and J. Gomez, "Flexible tag microlab development: gas sensors integration in RFID flexible tags for food logistic," Sensors and Actuators B: Chemical, vol. 127, no. 1, pp. 2 -7 , Oct. 2007.

[7] E. Abad, F. Palacio, M. Nuin, A. Gonzalez de Zarate, A. Juarros, J. M. Gomez, and S. Marco, "RFID smart tag for traceability and cold chain monitoring of foods: demonstration in an intercontinental fresh fish logistic chain," Journal of Food Engineering, vol. 93, no. 4, pp. 394-399, Aug. 2009.

[8] J. Choo, J. Ryoo, and H. Choo, "Design of a flexible planar RFID tag antenna with low performance degradation from nearby target objects," Journal of Electromagnetic Engineering and Science, vol. 11, no. 1, pp. 1 -4, Mar. 2011.

[9] Z. J. Tang, J. Zhan, Z. F. Xi and Y. G. He, "Broadband UHF RFID tag antenna with a rectangular-loop feed and additional patches," Microwave and Optical Technology Letters, vol. 54, no. 5, pp. 1234-1236, May 2012.

[10] J. H. Lu and J. Y. Su, "Planar loop tag antenna with bandwidth enhancement for UHF RFID system," $M i-$ crowave and Optical Technology Letters, vol. 53, no. 11, pp. 2711-2713, Nov. 2011.

[11] J. Yeo, "Long range UHF RFID tag with a rectangular metallic cavity structure," Journal of the Korea Electromagnetic Engineering Society, vol. 10, no. 3, pp. 121-126, Sep. 2010.

[12] R. Bancroft, "Design of an integrated loop coupler and loop antenna for RFID applications," Microwave and Optical Technology Letters, vol. 51, no. 8, pp. 18301833, Aug. 2009.

[13] H. W. Son and G. Y. Choi, "Orthogonally proximitycoupled patch antenna for a passive RFID tag on metallic surfaces," Microwave and Optical Technology Letters, vol. 49, no. 3, pp. 715-717, Mar. 2007. 


\section{Dong-Beom Shin}

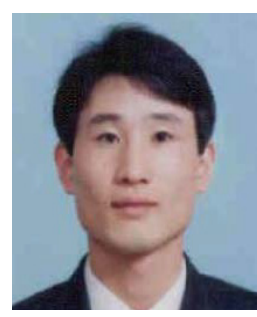

received the B.S., M.S., and $\mathrm{Ph} . \mathrm{D}$. degrees in electronics engineering from Chungnam National University, Korea, in 1991, 1993, and 2010, respectively. He joined Agency for Defense Development, in 1993 and engaged in the test and evaluation research related to military till 2000 . $\mathrm{He}$ joined Electronics and Telecommunications Research Institute (ETRI), in May 2000 and has been engaged in the research and development of high-speed router systems, EPON/GPON OLT systems, and RFID sensor tag $\&$ reader systems. Now, he is a principal member of engineering staff in IoT Convergence Research Department. His current research interests are design and implementation of RFID system.

\section{Jung Nam Lee}

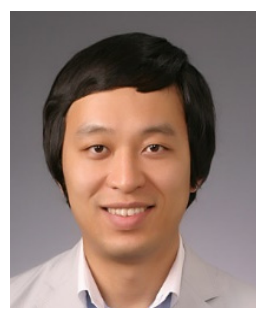

received the B.S. and M.S. degrees in Department of Information and Communication Engineering, Hanbat National University, Daejeon, Korea, in 2004 and 2006, respectively. He received the Ph.D. degrees in Radio Wave Engineering from Hanbat National University, Daejeon, Korea, in 2010. In joined the Mobile RF Research Team of Electronics and Telecommunications Research Institute (ETRI) where he is currently a senior member of engineering staff. His research interests are small antenna, RFID antenna, UWB antenna and small base station antenna design.

\section{Heyung-Sub Lee}

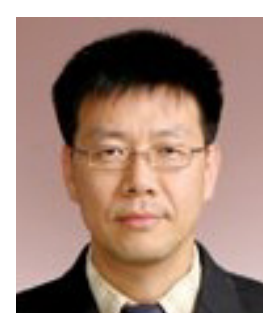

received the B.S., M.S., and Ph.D. degrees in electronics engineering from Chungnam National University, Korea, in 1985, 1994, and 2002, respectively. He joined Samsung Electronics in 1985 and had been engaged in the research and development of SRAM till August 1990. He joined Electronics and Telecommunications Research Institute, in September 1990 and has been engaged in the research and development of SDH based transmission system, high speed router system and optical premise network system, RFID System etc. Now, he is a principal member of engineering staff in IoT Convergence Research Department. His current research interests are technology development and service implementation of IoT.

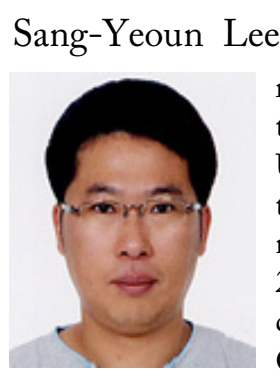

received the B.S. and M.S. degrees in electronics engineering from KangWon National University, Korea, in 1996 and 1998, respectively. He joined Electronics and Telecommunications Research Institute (ETRI), in Oct 2000 and has been engaged in the research and development of high-speed router systems, EPON/GPON OLT systems, RFID sensor tag \& reader systems and RFID security tag \& reader systems. Now, he is a principal member of engineering staff in IoT Convergence Research Department. His current research interests are technology development and implementation of RFID system.

\section{Byeong-Sam Kim}

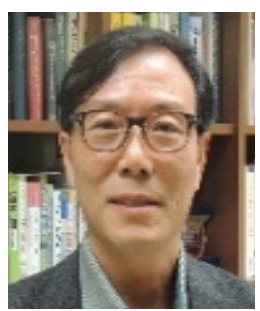

received the B.S., M.S., and Ph.D. degrees in food engineering from Pukyong National University, Korea, in 1983, 1985, and 2000, respectively. He joined Agricultural and Fishery Marketing Corporation in 1986 and had been engaged in the research and development of food distribution technology till April 1988. He joined Korea Food Research Institute (KFRI), in May 1988 and has been engaged in the research and development of $\mathrm{u}$-food system, food storage and distribution systems. Now, he is a leader in u-Food System Research Group in KFRI. His current research interests are $\mathrm{u}$-Food System converging with ICT and food technology. 